\title{
Study of Cadre Online Inquiry Learning System
}

\author{
Qian Dongming \\ $\mathrm{ERCDE}^{2}$ \\ East China Normal University \\ Shanghai, China \\ dmqian@dec.ecnu.edu.cn
}

\author{
Qiu Huixian \\ Educational InformationTechnology \\ East China Normal University \\ Shanghai, China \\ qiuhuixian@163.com
}

\author{
$\mathrm{Qu} \mathrm{Yu}$ \\ Shanghai Cadre Online Learning City Service Center \\ Organization Department of CPC Shanghai Committee \\ Shanghai, China \\ quy@shgb.cn
}

Abstract-With the diversified development of online learning technology and cadres being familiar with the new IT technology, traditional mode of cadre online learning already can't satisfy the students, which is a unidirectional teaching mainly on three-screen courseware. In China, through integrating cadres' characteristics and the development of online learning technology with mode of cadre online learning, cadre educational workers practice concept of lifelong learning to make cadre online learning be two-way, interactive and collaborative. We summarize the current situation of Chinese cadre online learning and inquiry learning system at home and abroad; then based on characteristics of adult learning, optimize strategies of cadre online collaborative learning and exploit cadre online inquiry learning system; introduce practice of the system in Shanghai Cadre Online Learning City for popularization and further promotion of cadre online education, and applying to solve practical problems.

Keywords: cadre online learning; Inquiry learning system; adult learning

\section{INTRODUCTION}

Since formally proposed by the Paul Lengrand in 1965 , the lifelong education received extensive attention all over the world. In china, the government is paying more and more attention to the cadre education,"According to cadres' characteristics, cadre education should integrated various teaching methods, like lecture, inquiry, case, analog, experiential to improve teaching quality[1].",'Innovative training methods. Popularize case learning, short-term training andmicroteaching.Improve lecturing teaching, and popularize inquiry teaching[2]." At present, online learning has become an important part of cadre lifelong learning. But generally, cadre online learning has many problems, like single teaching mode, the gapbetween theory and practice, too little collaboration between students. The features of online inquiry learning, which are openness, autonomy, cooperation, practice and process, can effectively solve the problems [3].

\section{Situation OF ChINESE CADRE ONLINE INQUiRY LEARNING SYSTEM}

\section{A. Current Situation of Chinese Cadre Online Learning}

Since Shanghai cadre online learning city run online in 2005, which is the first large-scale cadre online learning system in China, more than $90 \%$ places followed. For example, in Shanghai, from 2005 to 2012, it has nearly 380000 students, and the annual average is nearly 50000 people.More than $96 \%$ students register successfully every year. Thethrough rate is nearly $90 \%$. In recent years, cadre online learning system have provided interactive learning system with social learning elements, like BBS, blog, micro-blog and so on.These all provides opportunities for students to collaborate online.

However, according to statistics, cadre online learning is still facing many problems currently:Firstly, the majority of working students are lack of motivation. And they have low self-efficiency, high turnover rate, too fragmented time, andonly for organizational requirementsin the learning process [4]. Secondly, having less main goal, students manage knowledge hard. Due to broad and messyknowledge, they do not integrate deeply what they have learned so that the systematic concept system can't be formed. Thirdly, no effective online learning community. Cadre online learning resources are always one-way and web-based, accompanied by some mobile learning resources. So cooperation between students are too few to form a learning community effectively. Fourth, focusing on theory instead of practice [5]. Cadres' characteristics require knowledge combiningwith practice to service people.

On the basis of universal ways of cadre online learning, it is necessary to combine the advantages of network with cadres' characteristicto further deepen the effectiveness and relevance of cadre online learning. Therefore, it requires to carry out online inquirylearning to play openness, autonomy, collaboration, practice and process of online learning through setting specific goals of learning theme. Itwill effectively stimulate cadres' endogenous motivation to participate in online learning to form a learning communityby a series of cooperative learning tasks.

\section{B. Situation of Inquiry Learning System}

Chinese education put forward "Inquiry Learning", which is similar to "Project Learning" and "Problem -based 
Learning", which are popular in international [6]. In 1983, Slavin proposed six characteristics about collaborative learning: group target, all responsibility, justice and success opportunity, group competition, task specialization, catering to individual needs [7].In 2002, Johnson brothers abstract the characteristics of collaborative learning: interdependence, f2f-interaction, all responsibility, social skills, group reflection [8]. "Group", "interactive", "competition" etc. reflect the importance of collectivity, participation and process in the collaborative learning.To the early $21 \mathrm{st}$, inquiry learning is carried out through dozens of countries.

Currently, inquiry learning is usually used for medical and basic education in China. Due to thefive basic characteristics of inquiry learning, focusing on ability, research, process, participation and collectivity, all kinds of face-to-face inquiry learning activities are very popular.

After entering the $21 \mathrm{st}$, due to the popularity of Internet and the rise of online learning, inquiry learning began to be networked.The online inquiry learning is a typical kind of CSCL (Computer Supported Collaborative Learning).In the world, the online teaching aids platforms have been taken for inquiry learning system by more high educational institutions. Online inquiry learning is that teachers or students confirm the research topic or project,and students useonline resources to explore, discovery, collection, analysis and process information collaborativelyin group under teachers' guidance, to solve practical problems and conclude in the end. Inquiry learning system generally refers to the platform which can promote collaboration between groups and study more deeply, facilitate sharing and integration of students' knowledge and skills.

Zhao Jianhua, divided the function which is based on collaborative learning into six types [9].

- Facilitating inquiry, comprehension and conversation;

- Promoting knowledge construction and providing the platform for demonstrating points, shaping study theme and finding consensus on new area;

- Maintaining vital data and expanding memorial function;

- Long-distance communication;

- Enriching the categories of reflection through cooperation;

- Supporting the design and implement of collaborative activity conducted by teachers.

At present, there are numerousonline inquiry learning system, typically like CSILE System, Kolumbus System,
CoMentor System and etc. The three system are the most typically results of applicationof inquiry learning, which have already applied in teaching practice.

Studies show that there is few inquiry learning system in China, especially in adult education and cadre education. The characteristics of Cadre students determineit is especially suitable for cadres to learn in online inquiry learning system.

\section{DESIGN OF CADRE ONLINE INQUIRY LEARNING SYSTEM}

The development of online inquiry learning needs a good platform, appropriate theme, organized participants, proper guidance and rigorous process specifications. The participants have certain knowledge background, certain IT skills and enthusiasm; Theme settings should be suitable for participants' knowledge and ability without clear answer, which need students communicate and collaborate. The process specification is to ensure inquiry learning activities carrying out smoothly, and proper guidance refers to grasp the direction of whole activity to make participants achieve much.

According to the characteristics of adult learning and principles of learning activity design, the design of cadre online inquiry learning system also need to combine $\mathrm{f} 2 \mathrm{f}$ inquiry learning process with cadre learning management system, and make full use of the characteristics of online learning system.

\section{A. Characteristic of Adult Learning}

The adult education theory, which is provided by Malcom Knowles, is that adult learners have five basic assumptions: (1) they have an independent self-concept and can guide their own learning; (2) they accumulate a lot of life experience like reservoir, which is rich for learning; (3) learning needs are closely related to the changing social roles; (4) focusing on problems to learn and be interested in knowledge applied immediately; (5) learning motivation are mainly internal rather than external [10].

According to eight-year practical experience of online teaching in Shanghai Cadre Online Learning City, the current characteristics of adult online learning are: (1) Learners are both learners and experts in some area, (2) have rich knowledge and theoretical and practical experience to share, (3) have certain information technology skills, and some learning self-control, and time management ability, (4) have common interests, (5) be familiar with f2f collaborative inquiry learning and work process in reality.

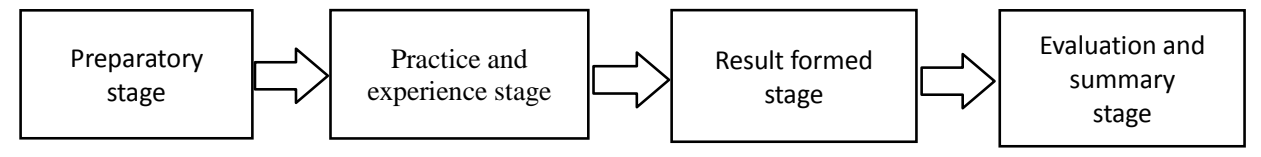

Figure1. General process of inquiry learning.

\section{B. System Design Thought}

\section{1) Basic learning process}

Inquiry learning can be divided into four stages generally: preparatory stage, practice and experience stage, result formed stage and evaluation summary stage. Each stage has different tasks and joins each other to become a whole, as shown in fig.1.

According to characteristics of online learning, students will study in system through the following four types: 
- Large synchronous and small asynchronous learning style. Big synchronization refers to that in entire process of inquiry learning, learning process must be synchronized with the stipulated time of learning activities; Small asynchronization refers to student bein specific online learning, namely students can choose time freely for study and discussion in some teaching activity time.

- Discuss mostly in asynchronous way with synchronization in support. Students and experts mainly discuss asynchronously unless in some important stage.

- Instructor-led teaching method involved with experts wholly. Theme experts participate in the whole learning process, including organize group discussion, grasp direction and supervise learning at any time to avoid the migration of theme when in interaction and lack of initiation. The subject of inquiry learning is learner. But this method of online learning, which is around the theme, belongs to incompletely free learning style.

- Guide method with regulatory mechanism of discussion. Participants in the discussion can speak freely about problem. But in this process, Students' comments will be supervised and managed by backstage. Once a serious deviation from the theme of the content is discovered, it will be handled immediately to ensure the discuss content healthy, safe and orderly.

The above four major learning method fully reflects the deep interaction, information aggregation, collective thinking, collaborative construction, multiple coordination in collaborative inquiry learning [11].

\section{2) Design of system role}

The design of system role decided system function. Typical learning system generally have four or five roles. For example, Moodle system is divided into five kinds of roles as system administrator, course administrator, teacher, assistant and student; LAMS (Learning activity management system) is divided into four kinds of roles as administrator, designer, supervisor and learners.
We consider that cadre online inquiry learning system has seven roles on basis of cadre $\mathrm{f} 2 \mathrm{f}$ inquiry learning and characteristics of network: system administrator, theme administrator, class teacher, general student, group leader, expert, bystander.

- System administrator: responsible for the overall coordination and system operations;

- Theme administrator: course initialization (course basic information management, preschool assessment management, etc.), course process management (collaboration and communication management, student management, phase audit, etc.);

- Class teacher: course process management;

- Group leader: Except for general students' rights, they also can do information review, phase audit, public information management and discussion settings;

- Expert: Except for general students' rights, they also can do information review, phase audit and individual communication.

- Bystander: view entire learning information, but none participation and management. This role helps others acquire information about learning and teaching.

\section{3) Basic Activity}

In 1998, Barron have pointed out that the tasks or activities with inquiry and technical supportcan encourage students to construct the frame [12]. Inquiry learning activities generally involved with the technology, like BBS, wiki, chat and other common online learning technology. Based on these, it can extend some extended activities, including knowledge display, sharing resources, chat, BBS, bulletin board, selecting test, Q \& A, uploading files, SMS, voting, survey and so on.

According to the particularity of cadre online education and the characteristics of inquiry learning, learning activitiescan be set like Figure 2, which aredivided into five stages:

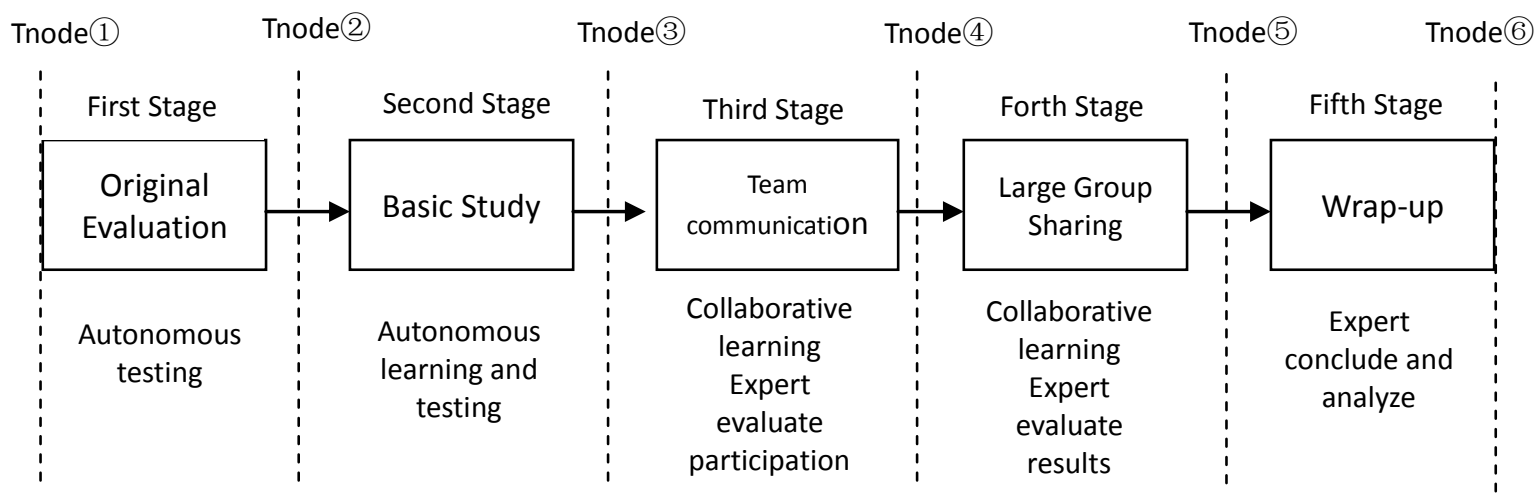

Figure2.Activity model of cadre online inquiry learning 
Firstly, original evaluation. Through independent testing, Students are assessed to ensure that the cadres who join the research have a basic knowledge and the interaction of several stages can be carried out, and toavoid the big difference. Meanwhile, we need to group through the assessment of the starting point. Group learning is an important way of inquiry study, which has various ways, such as free grouping, homogeneous grouping, heterogeneous grouping, and so on.Besides, though online learning, the number of group membercanalso be studied.

Secondly, Basic learning. Aimed tospecific inquiry subjects, students in this stage are provided learning resources. Students can study learning resources independently and spontaneously, and gather related information through various way to form their own preliminary solution. This stage is mainlyself-study and self-development of student.

Thirdly, team communication.Under the guidance of experts, trainees carry out effective collaborative learning by grouping, who can use BBS, WIKI and other tools to communicate and collaborate to propose, share and evaluate their views. At last, the team reach an agreement to research results through discussing.

Fourthly, large group sharing. After reaching a team consensus on research achievements, in order to form a consistency of the whole subject, they share the achievements and knowledge between teams from a higher level. According to the nature of subject, these final results could be a best knowledge construction, or multiple knowledge construction.

Fifthly, wrap-up. At this stage, through autonomous learning, sharing and collaborative construction, students have formed research results with characteristics of students. At the last learning stage, experts summarize and analyze to evaluate research process and results, so that students can learn and understand the theme, process, results of inquiry learning.

The above five activities each has starting and cutoff point through principle of large synchrony and small asynchrony. Students can study and publish their views freely on the Internet in any activity.

\section{Basic Flow of System}

According to the design of online inquiry learning activity, the basic process of system can be determined as shown in fig. 3.

The function of interaction and resource sharing are used to the practice and experience stage and results formed stage. Students can use resources provided by experts or through other channels to obtain information, communicateand collaborate within the team, share experiences in big group, publish learning tips, and thus for the knowledge integration. According to the research process and requirements, interaction and resources sharing can be launched repeatedly.

Learning evaluation in the traditional cadre online learning system, which generally adopts unit exam, belong to summative evaluation. As inquiry learning canboth grasp knowledge andenhance capabilities of learning analysis, which is a combination of a series of learning activities, it is more suitable to use the procedural evaluation. Duringthe time of designingcadre online learning system, evaluation and feedback run through all inquiry learning. The entire evaluation system consists of four parts: 1) original evaluation, students take the individual level test.If failed, theycan choose to learn the basics and then test again until achieving the study conditions. 2) During the research, it is necessary to evaluate the primary research results and the students also need to present their research results in the shared stage.3) During the research, it is necessary to the assessment of students' attitude and learning initiative and participation. So inprocess of group sharing, there is learning interaction degree need to evaluate, such as the number of BBS tips. 4) Online inquiry learning, is a collective learning process. When concluded, teacher will evaluate the research results. The results of these four parts eventually become the last grade about this inquiry learning. 


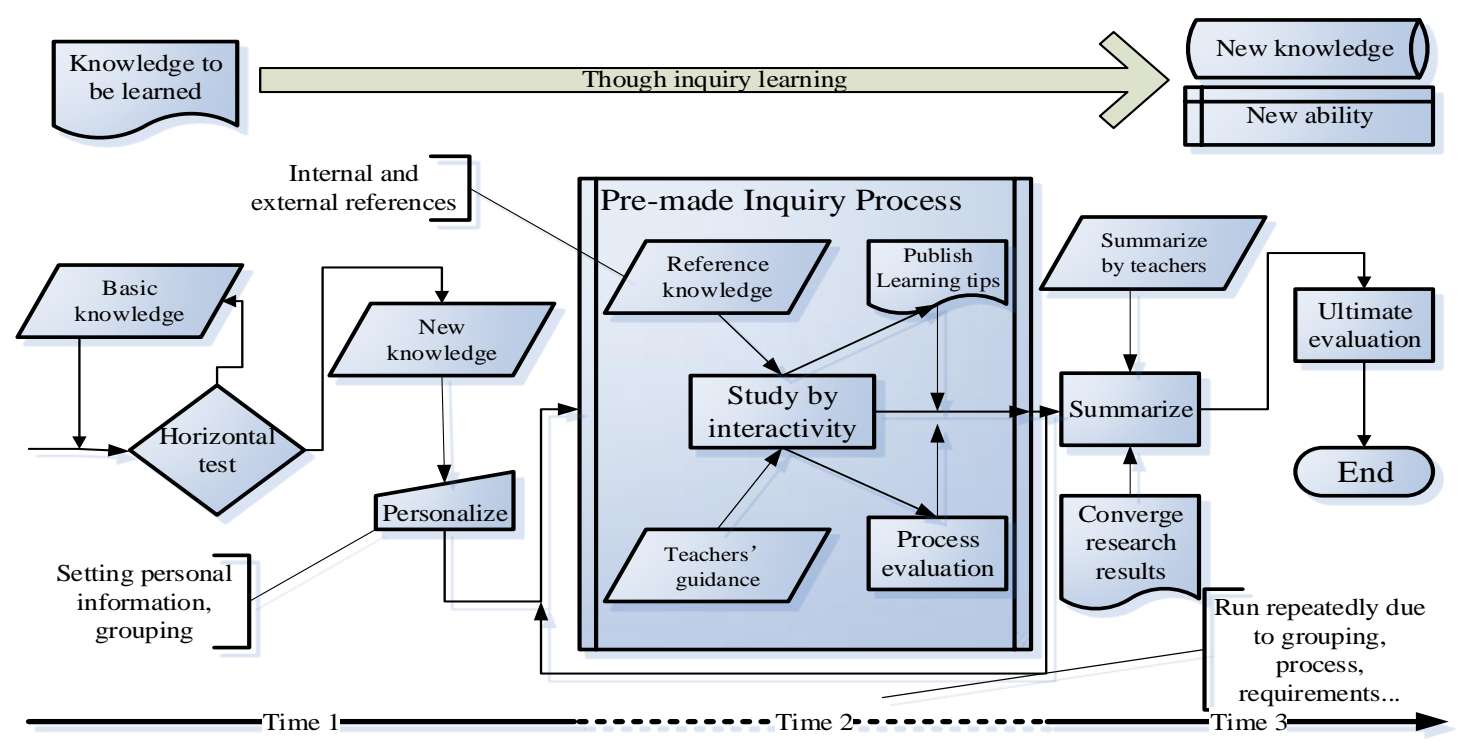

Figure3. Basic Function

\section{PRACTICE OF CADRE ONLINE INQUIRY LEARNING SYSTEM}

\section{A. Basic Structure of "Online Thematic Class"}

The basic structure of "online thematic class" is shown in fig.4. The system can be divided into foreground and background. The former one refers to course study management module. And other refers to course maintenance management and system maintenance management module.

- Course learning management: original evaluation stage, subject learning stage, group discussion stage, express and sharing stage, summary and evaluation stage.

- Course maintenance management: courseware content management, resource management, test management, discussion management, course schedule management.

- $\quad$ System maintenance management: basic parameter management, student information management, discussed content management, communication management, summary report management.

\begin{tabular}{|c|c|c|}
\hline \multicolumn{3}{|c|}{ Register and login } \\
\hline $\begin{array}{l}\text { Course study } \\
\text { management }\end{array}$ & $\begin{array}{c}\text { Course maintenance } \\
\text { management }\end{array}$ & $\begin{array}{l}\text { System maintenance } \\
\text { management }\end{array}$ \\
\hline 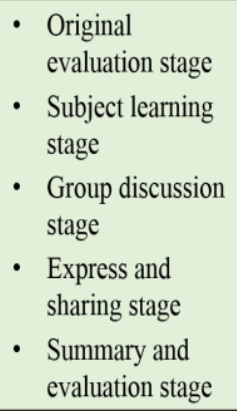 & $\begin{array}{l}\text { - Courseware } \\
\text { content } \\
\text { management } \\
\text { - Resources } \\
\text { management } \\
\text { - Test management } \\
\text { - Discussion } \\
\text { management } \\
\text { - Course schedule } \\
\text { management }\end{array}$ & $\begin{array}{l}\text { - Basic parameters } \\
\text { management } \\
\text { - Student } \\
\text { information } \\
\text { management } \\
\text { - Discussed content } \\
\text { management } \\
\text { - Communication } \\
\text { management } \\
\text { - Summary report } \\
\text { management }\end{array}$ \\
\hline
\end{tabular}

Figure4. Fundamental components

\section{B. Application of "Online Thematic Class"}

Since the first application of "online thematic class"in 2010, Shanghai Cadre Online Learning City have launched nearly 150 online thematic class" until the end of 2013. It has more than 600 people per class. And over $70 \%$ course resource belong to independent development. There are more than 3600 original posting and 50000 comments.

The learning style of "online thematic class", welcomed by cadre students, have changed the traditional problems, like single learning means, lack of interactions, etc.

But compared with expected results, the training effect of "Online thematic class" should be improved. Most students only post as required, instead of more communication and collaboration with experts and classmates. And it also needs more efforts on theme design, providing resources, guide of interaction, etc.

Pea, who is expert of educational technology in USA, pointed out: we need to pay close attention consciously on 
produce and development of CSCL. It will not only be a kind of method, but also a new perspective of learning and education[13]. In the new media era of digital learning, interactive methods will present the trend of fragmentation and mobilization. The resource of inquiry learning in the future will take over micro courses, and so mobile instant messaging does by interactive means. Based on these, the new version of online inquiry learning system will start again.

\section{ACKNOWLEDGMENT}

Thanks for the fund program of this paper, which is Shanghai science and technology commission project: The research of key technology for Shanghai cadre education platform (12511509700) in 2012.

\section{REFERENCES}

[1] Cadres' Education and Training Work Regulation (Trial)[Z]. 2006.

[2] Cadres' Education and Training Reform Program (2010- 2020)[Z]. 2010.

[3] Xiao Ying, Shi Lijun, Yuan Bo, Tan Bin and Zeng Xianwen, "The Design and Implementation of Platform for the online inquiry learning, " Journal of Jinggangshan University (Natural Science), Vol.33, Nov. 2012.

[4] Qian Dongming, Jueqi Guan, Yu Qu and Shen Kai, "Study on the Effects of Trainee's Characteristics on Cadres Online Learning - A Case Study of Shanghai Cadres Online Learning Platform," Open Education Research, Vol.1, 2011, pp.92-96.

[5] Hua Ying, "The Research and Implementation of Cadre Online Inquiry Learning Platform," Computer Applicated Technology, East China Normal University, 2007.

[6] Liu Zhiyun," Discussion on the Characters and Origins of Inquiry Learning," Research in Teaching, Vol.29, Jan. 2006.

[7] Slavin, R.E, "Cooperative learning: Applying contact theory in desegregated schools," Journal of Social Issues, Vol.41, pp.45-62, 1983.

[8] Johnson, D.W. and Johnson, R.T.," Cooperative learning and social interdependence theory," In R.S. Tindale (Ed.), Theory and research on small groups [electronic resource]. New York: Kluwer Academic Publishing, pp. 9-36, 2002

[9] Zhao Jianhua and Li Kedong," The Principle and Basic Structure of CSCL (1)," E-education Research, Vol.5, 2003.

[10] SharanB. Merriam," The New Update on Adult Learning Theory," Jossey-Bass, May 2001.

[11] Zhu Zhiting, Wang Youmei and Gu Xiaoqing," Collaborative Learning: a Framework of Learning Technology System Catering to Knowledge Era," China Educational Technology, Vol.4, 2006.

[12] Barron B.J.S., Schwartz D.L., Vye N.J., Moore A., PetrosinoA., et al.," Cognition and Technology Group at Vanderbilt (1998) Doing with understanding: Lessons from research on problem- and project-based learning," The Journal of the Learning Sciences 7,271-311.

[13] Ragoonaden, K," Collaborative learning via the Internet," Educational Technology and Society, Vol.3, 2000. 